\title{
Perspectivas acerca da aposentadoria na percepção de docentes de uma universidade pública federal
}

\author{
Izabel Cristina Ferreira Borsoi ${ }^{1}$ e Flavilio Silva Pereira ${ }^{2}$ \\ Universidade Federal do Espírito Santo (Vitória, Espírito Santo, Brasil)
}

\begin{abstract}
A aposentadoria tem sido, para a maioria dos trabalhadores, motivo de inquietação devido a sentimentos de incerteza sobre a vida na ausência de vínculo laboral. Este artigo visa analisar planos e perspectivas de aposentadoria entre docentes efetivos de uma universidade pública federal brasileira. A primeira fase da pesquisa abordou 96 professores (56 homens e 40 mulheres) a partir de um instrumento estruturado com perguntas abertas e fechadas. A segunda fase consistiu em 18 entrevistas com participantes da etapa anterior. Os resultados indicaram que: 1) em sua maioria, os docentes tenderiam a continuar trabalhando ao se aposentarem, seja em atividades acadêmicas ou não, seja vinculados formalmente a uma instituição ou não; 2) muitos deles reservariam tempo para atividades de lazer e diversão; e 3) mais frequentemente que os homens, as professoras optariam por atuar em trabalhos não acadêmicos. Assim, parece mais evidente que, para a maior parte dos docentes, o momento da aposentadoria foi percebido como uma continuidade da vida ativa e produtiva, independentemente do tipo de trabalho ou atividade que fariam.
\end{abstract}

Palavras-chave: Perspectiva de aposentadoria, Docente, Trabalho, Lazer, Universidade pública.

Perspectives on retirement in the perception of professors of a federal public university

Retirement has been a source of concern for most workers because of feelings of uncertainty about life in the absence of employment ties. This article aims to analyze plans and perspectives of retirement among permanent professors of a Brazilian federal public university. The first phase of the survey approached 96 professors (56 men and 40 women) from a structured instrument with open and closed questions. The second phase consisted of 18 interviews with participants from the previous stage. The results indicated that: 1) most professors would tend to continue working when they retire, whether in academic activities or not, formally linked to an institution or not; 2) many of them would take some time out for leisure and fun activities; and 3) more often than men, female professors would choose to work in non-academic jobs. Thus, it seems more evident that, for most professors, the moment of retirement was perceived as a continuation of active and productive life, regardless of the type of work or activity they would do.

Keywords: Retirement perspective, Professor, Work, Leisure, Public university.

\section{Introdução}

\begin{abstract}
A preocupação com a aposentadoria tem sido cada vez mais crescente, tanto para os trabalhadores que dela se aproximam quanto para aqueles que ainda estarão no mundo do trabalho por muitos anos. Mudanças nas regras que a regulamentam - as quais resultam de reformas do regime de Previdência Social -, incertezas acerca da situação financeira e a expectativa de uma experiência de não trabalho são aspectos importantes que impactam a vida dos trabalhadores e podem ser motivos suficientes para gerar certo grau de insegurança e apreensão.

Este artigo tem o objetivo de analisar aspectos relativos às perspectivas e aos planos que professores e professoras de uma universidade pública federal traçam, visando lidar com o desligamento definitivo do quadro docente da instituição.

A aposentadoria deve ser compreendida como parte da realidade da vida profissional e laboral e, também, como consequência do processo de desenvolvimento dos indivíduos

1 Psicóloga, Doutora em Sociologia e professora do Departamento de Ciências Sociais da Universidade Federal do Espírito Santo (Ufes).

2 Cientista Social e Mestre em Ciências Sociais pela Universidade Federal do Espírito Santo (Ufes).
\end{abstract}


(Bressan, 2011). Assim, é temática presente no cotidiano dos trabalhadores de modo geral, em particular quando eles se veem expostos a situações de trabalho que exigem intenso desempenho e metas de produtividade que podem afetar sua saúde e sua vida para além da jornada laboral, quando estão diante de mudanças relacionadas ao tempo necessário para se aposentarem e, por fim, quando estão às vésperas desse evento.

Duarte e Melo-Silva (2009) apontam que a expectativa de trabalhadores que estão prestes a se aposentar é permeada por sentimento de insegurança, que pode decorrer tanto da instabilidade financeira como da ameaça da perda iminente do papel social. A situação de não trabalho aparece, entre outros aspectos, associada à inatividade e ao processo de envelhecimento, dentro de uma conotação negativa.

De um lado, a lógica capitalista valoriza o indivíduo que está imerso em um sistema considerado produtivo. Assim, a tendência é perceber os trabalhadores que se aposentam como improdutivos, inativos e, de certo modo, "dependentes" da sociedade. Essa representação que permeia o imaginário social pode acompanhar os aposentados ao longo de suas vidas como um estigma (Costa, Micali, Huamaní, Costa \& Lopes, 2016; Figueira, Haddad, Gvozd \& Pissinati, 2017). De outro lado, a aposentadoria está associada ao processo de envelhecimento do indivíduo. Então, é provável que, para muitos, "aposentar-se signifique ter envelhecido, pois a chegada da aposentadoria concretiza o momento em que se percebe que o tempo passou e é necessário finalizar o ciclo de trabalho" (Pereira, Moraes, Pereira \& Costa, 2016, pp. 53-54).

Aspectos como esses impactam as decisões de um trabalhador sobre quando se aposentar, bem como sobre o que fazer diante da situação de não trabalho. Nesse último caso, o problema se mostra bastante complexo, porque implica um determinado planejamento prévio e/ou a construção de novos projetos de vida, de modo que o tempo dedicado a rotinas organizacionais ou institucionais seja preenchido de alguma maneira. Bressan, Mafra, França, Melo e Loretto (2013), analisando a significação que servidores técnico-administrativos e docentes de uma universidade pública federal atribuem ao bem-estar na aposentadoria, afirmam que eles, no geral, não se preparam visando essa etapa da vida. Os participantes da pesquisa elegeram, como fatores fundamentais, a saúde e a tranquilidade financeira, mas praticamente não apontaram formas de ocupação do tempo na ausência do trabalho como aspectos essenciais para esse sentimento de bem-estar. Essa, por sinal, é uma situação recorrente entre aqueles que estão próximos a se aposentar.

No caso dos docentes, em particular de universidades públicas, a problemática da aposentadoria precisa levar em conta alguns elementos específicos, dentre os quais destacamos: 1) trata-se de uma categoria com elevada qualificação; 2) em muitas situações, sua formação profissional permite atuar fora do ambiente acadêmico, como pode ocorrer a docentes nas áreas da saúde, do direito e da engenharia, por exemplo; 3) o trabalho acadêmico é um tipo de atividade que possibilita determinado nível de autonomia em torno de como atuar no âmbito da instituição e certo grau de flexibilidade na organização da jornada; 4) e, por fim, é uma profissão que tem visível reconhecimento social.

Se, por um lado, o trabalho docente pode ser caracterizado por seus aspectos positivos, conforme exposto, por outro, ele vem, cada vez mais, se aproximando de uma lógica produtivista pouco condizente com a natureza da atividade acadêmica, por excelência. Assim, observamos que tem sido crescente a imposição de parâmetros de produtividade e a diversificação das atividades que os docentes precisam assumir, as quais podem ir além do que se define como trabalho acadêmico propriamente dito, como mostram Alvarez (2004), Borsoi (2012), Pizzio $\&$ Kein (2015) e Sguissard e Silva Junior (2009). Aspectos como esses têm levado professores e professoras a manifestarem, muitas vezes, mais descontentamentos e sofrimento do que prazer e bem-estar em relação à própria profissão. A rotina de trabalho passa a ser vista, quase 
sempre, como massacrante, não oferecendo tempo livre efetivo para a realização pessoal e para as vivências prazerosas, ficando isso "num esboço para quando alcançar a aposentadoria", como apontam Bruns e Abreu (1997). Diante disso, julgamos importante analisar a percepção sobre as perspectivas que docentes de uma universidade pública federal constroem em torno de sua aposentadoria.

Para dar conta da discussão em tela, lançamos mão de resultados de uma pesquisa realizada com o objetivo de analisar implicações da precarização do trabalho e das exigências de produtividade no modo de vida e na saúde de professoras e professores efetivos. Portanto, não se trata de uma pesquisa voltada exclusivamente para questões relativas à aposentadoria. O tema foi abordado dentre um conjunto de aspectos relacionados a atividades acadêmicas, jornada de trabalho, saúde, maneira de organizar a vida fora do ambiente institucional etc. ${ }^{3}$.

\section{Método}

A pesquisa foi dividida em duas etapas. Na primeira, foram envolvidos 96 docentes de um universo de 403, sendo 56 homens (58,3\%) e 40 mulheres (41,7\%), distribuídos entre 18 departamentos ${ }^{4}$. A idade média dos participantes foi de 46,7 anos, variando entre 26 a 68 anos. A média de tempo de trabalho na universidade era de 14,6 anos, a moda, 14 anos, e a variação entre máximo e mínimo foi de menos de um ano a 34,7 anos.

Nessa fase, os professores e professoras foram convidados a responder um conjunto de perguntas, fechadas e abertas, de um instrumento que denominamos de "Protocolo de estudo sobre trabalho docente", desenvolvido especificamente para aquela pesquisa.

$\mathrm{Na}$ segunda etapa da investigação, foram realizadas entrevistas individuais com 18 dos professores e professoras que responderam o referido protocolo. Esse grupo foi constituído intencionalmente, considerando um conjunto de resultados de cunho quantitativo.

No caso do protocolo, além de perguntas objetivas, havia um conjunto de itens em que cada participante tinha a liberdade de anotar o que considerasse relevante a partir de uma elaboração textual própria. No artigo em tela, consideramos respostas objetivas e descritivas a perguntas relacionadas às perspectivas para a aposentadoria. Essas respostas foram categorizadas de maneira a permitir serem analisadas a partir de estatística descritiva.

Julgamos importante esclarecer que compartilhamos com Bauer, Gaskell e Allum (2002) o princípio de que não é possível quantificar fatos sociais sem, antes, identificar e qualificar as categorias sociais que os caracterizam. Sendo assim, os resultados quantitativos apresentados neste artigo expressam tendências de percepções que os docentes que participaram da pesquisa construíram acerca de seus planos e perspectivas para a aposentadoria. O que fizemos foi categorizar suas respostas de maneira a permitir interpretá-las a partir de determinado campo teórico.

No que diz respeito às entrevistas, elas possibilitaram questionar sobre percepções, sentimentos e expectativas que os professores e as professoras não poderiam expressar a partir de um protocolo de perguntas previamente estruturadas. Os aspectos abordados eram amplos, o que envolvia várias dimensões do trabalho acadêmico e da política universitária, bem como questões relativas à saúde, ao modo de vida e, também, às perspectivas para aposentadoria.

3 O projeto foi submetido à avaliação do Comitê de Ética em Pesquisa da universidade envolvida na pesquisa, sob registro n⿳o 72/2009. A pesquisa de campo teve início no segundo semestre de 2009 e foi concluída, efetivamente, no primeiro semestre de 2012.

4 Parâmetros para amostra em questão: margem de confiança de 95\%, com erro amostral de 8,7\%, considerado acima do usual, que é de $5 \%$. 


\section{Trabalho acadêmico, trabalho não acadêmico e lazer: o que fazer ao se aposentar?}

Entre os anos de 1995 e 2005, principalmente, a universidade em que a pesquisa foi realizada iniciou um processo significativo de renovação no seu quadro de professores. Apenas naquele período houve aumento de 33\%, saltando de 896 para 1.190 docentes efetivos (Sguissardi \& Silva Junior, 2009). Em meados de 2010 - momento em que a pesquisa de campo estava em andamento - havia 1.200 professores $^{5}$, tendo ocorrido um crescimento de $0,8 \%$ em relação a 2005 , período em que houve maior ampliação em termos de quantidade de cursos e de matrículas ${ }^{6}$.

Nesse ínterim, as contratações de novos docentes integravam o plano de expansão e reestruturação da instituição - e não necessariamente tinham o propósito de substituir aqueles que haviam se aposentado. Por ocasião da pesquisa, 18,8\% dos participantes tinham menos de quatro anos de trabalho, 36,5\% entre quatro e 14 anos, 22,9\% entre 15 e 24 anos e 21,9\% estavam com 25 anos ou mais. Isso significa que se tratava de uma população com tempo de trabalho muito variado e com um número significativo de docentes distantes da aposentadoria. Entretanto, havia, também, muitos professores e professoras próximos a se aposentarem, ou que já poderiam estar aposentados. Convém registrar que ao menos 33,3\% dos integrantes do grupo se encontravam com mais de 50 anos, entre os quais alguns docentes com idade entre 60 e 68 anos de idade.

Na primeira etapa da pesquisa, os docentes depararam com uma pergunta que dizia respeito, especificamente, às perspectivas acerca da aposentadoria: "O que você planeja fazer quando se aposentar?". Aqui, a sistematização dos dados levou em conta respostas múltiplas para cada um dos participantes. Sendo assim, houve casos em que um mesmo respondente planejava mais de um tipo de atividade ao se aposentar.

Os resultados apontaram que quase metade dos docentes (49\%) indicava planos de realizar atividades voltadas para o lazer ou para algo lúdico que pudesse ser considerado uma espécie de rompimento com as rotinas de trabalho. Nessa categoria incluímos todos os que responderam que se dedicariam ao lazer $(41,7 \%)$, a algum tipo de hobby $(3,1 \%)$ ou, ainda, a atividades artísticas, como música, fotografia e artesanato (4,2\%).

$\mathrm{Se}$, de um lado, um número elevado de professores e professoras informou planos de se dedicar a atividades distantes do trabalho, de outro, um percentual ainda mais expressivo indicou que eles pretendiam continuar trabalhando. Nesse caso, $62,6 \%$ planejavam ou se manter atuando em trabalho acadêmico - diretamente vinculado, ou não, a uma universidade ou faculdade -, ou se dedicar a atividades não acadêmicas ${ }^{7}$. Nesse último caso, os docentes se dividiram. Parte deles declarou que buscaria trabalhos que, apesar de desvinculados do meio acadêmico, estavam relacionados, de alguma maneira, à sua própria área de atuação na universidade. Desse modo, professores e professoras dos cursos de Medicina e Psicologia afirmaram que trabalhariam com a clínica em suas especialidades, docentes dos cursos de Engenharia indicaram que fariam consultorias em suas próprias áreas de atuação etc. Outro grupo, no entanto, informou que almejava atividades de trabalho muito diferentes de sua área de conhecimento acadêmico. Aqui, tais escolhas ficaram mais evidentes nas entrevistas, como apontam os relatos de docentes dos departamentos de Administração e Economia.

5 Informações extraídas do site oficial da universidade em junho de 2010.

6 De acordo com dados obtidos no site oficial da própria universidade, em 2018 o quadro docente da instituição chegou a 1.780 professores efetivos, o que significa um crescimento de $32,6 \%$ nos últimos oito anos.

7 Lembramos que esses resultados tiveram como base respostas múltiplas para cada um dos participantes, como informado anteriormente. Então, houve casos em que um mesmo docente indicava o desejo de realizar mais de um tipo de atividade ao se aposentar, como se dedicar mais ao lazer e, também, se manter trabalhando. 
Agora estou me preparando para minha aposentadoria. Eu me aposento daqui a dez anos. Então, quero fazer um curso de Psicologia. Quero a chancela do que regulamenta a profissão no mercado. Eu quero consultório. A outra coisa é que eu tenho um projeto social. Eu já comecei, mas eu quero continuar depois da minha aposentadoria. Então o curso de Psicologia vai me ajudar nisso (Mulher, 52 anos).

Quero criar um instituto de treinamento e educação filosófico-político, continuar minhas pesquisas botânicas e meus estudos ambientalistas, ampliar minhas experiências na produção dos próprios alimentos (Homem, 51 anos).

As perspectivas tratadas nas falas não parecem estar relacionadas à necessidade de preencherem o tempo livre da obrigatoriedade do trabalho formal. Na realidade, esses projetos podem indicar um desejo que muitos docentes já traziam consigo. Isso se mostrou plausível ao analisarmos a relação entre a pergunta sobre as perspectivas de aposentadoria e outra que pedia que respondessem "se pudessem escolher outro trabalho, qual seria?". Nesse caso, quase a metade dos professores e professoras apontou planos de aposentadoria centrados em atividades que coincidiam com o (ou se aproximariam do) trabalho que escolheria, caso pudesse mudar de profissão. Convém salientar que pelo menos 29,6\% dos docentes que declararam que, ao se aposentarem, fariam atividades muito diferentes do trabalho acadêmico, também informaram que, se pudessem, escolheriam outra forma de atividade laboral. Por sua vez, aqueles que não escolheriam outra profissão, que não a docência, apontaram como perspectiva de aposentadoria continuar trabalhando em suas áreas acadêmicas.

Como afirmamos anteriormente, a primeira análise contemplou múltiplas respostas para cada um dos docentes, não discriminando aqueles que especificavam uma única forma de atividade. Diante disso, sistematizamos os resultados de modo a identificar os professores e professoras que disseram planejar exclusivamente uma perspectiva de atividade e aqueles que buscavam conciliar mais de um tipo de atividade, como mostra a Tabela 1.

Tabela 1. O que você planeja fazer quando se aposentar

\begin{tabular}{|l|c|c|}
\hline \multicolumn{1}{|c|}{ Planos após aposentadoria } & Freq. & \% \\
\hline Citou somente atividades de trabalho & 34 & 35,4 \\
\hline Citou atividades de trabalho conciliadas a lazer, hobby ou arte & 25 & 26,0 \\
\hline Citou somente atividades de lazer, hobby ou arte & 20 & 20,8 \\
\hline Atividade não específica & 17 & 17,7 \\
\hline Total & 96 & 100 \\
\hline
\end{tabular}

Fonte: Pesquisa direta.

Esse novo arranjo apontou, mais uma vez, maior tendência de os professores e professoras construírem suas perspectivas de aposentadoria em torno do trabalho. Nesse caso, os resultados mostram que $35,4 \%$ dos participantes informaram que realizariam apenas atividades de trabalho após se aposentarem. Esse percentual sobressai em relação aos $26 \%$ daqueles que indicaram que pretendiam conciliar trabalho com outras atividades. Embora sejam significativamente prevalentes as perspectivas de se manterem trabalhando após a aposentadoria - o que será discutido mais à frente -, chama atenção os 20,8\% dos docentes que assinalaram a pretensão de se dedicarem somente a atividades de lazer e diversão. Considerando a especificidade desse dado, cabe analisá-lo levando-se em conta, também, os resultados das entrevistas realizadas. 
Entre os entrevistados, notamos que o desejo de se afastarem completamente do trabalho estava, em geral, associado a sentimentos de sobrecarga e de saturação em relação ao cotidiano na universidade. As falas a seguir são de docentes que enfatizaram estar trabalhando no limite de suas capacidades e que manifestaram descontentamento com o grau de competição e de exigências de produtividade em seus próprios departamentos. Aqui eles se remeteram ao que fariam quando se aposentassem:

Daqui a seis anos eu saio, eu pulo fora. Quero pegar estrada, ter um cartão de crédito para botar um diesel e sair por aí. Honestamente, eu estou pensando em dar um jeito para mim (Homem, 54 anos).

Nada. Creio que já terei trabalhado demais até lá, já que trabalho informalmente desde os seis anos de idade. Dessa forma, ao me aposentar, aproveitarei, ao máximo, o tempo livre que me restar para viajar muito e fazer as coisas que, no momento, o tempo não me permite realizar (Homem, 48 anos).

Talvez clinicar, dar aulas, se me pagarem muito [ênfase na palavra muito]. Viajar e, quem sabe, fazer nada (Mulher, 49 anos).

"Eu pulo fora" e "nada" são expressões que indicam a busca de se esquivar de qualquer possibilidade de trabalho, de obrigação ou de compromisso profissional. $O$ tempo livre das atividades laborais precisaria, então, ser preenchido de outra forma, nesse caso, basicamente com atividades lúdicas e prazerosas, como "pegar a estrada" e "viajar". O desejo de viajar foi recorrente não apenas nas entrevistas, mas também nas respostas à primeira fase da pesquisa, e normalmente aparecia seguido de referências a outras atividades de lazer.

Esse conjunto de expectativas pode ser entendido como uma necessidade de viver experiências que reflitam a conquista de liberdade e o rompimento com a rigidez das rotinas laborais, como apontam Duarte e Melo-Silva (2009). A aproximação da aposentadoria costuma ser permeada de um conjunto de expectativas em torno da possibilidade que o trabalhador vislumbra de poder usufruir o tempo - antes dedicado ao trabalho - com atividades quase exclusivamente destinadas ao lazer. Em alguma medida, essa escolha de plano pode estar relacionada a condições econômicas que permitem mantê-lo e, também, a aspectos de ordem psicológica. É importante alertar, no entanto, que pode ser um equívoco "imaginar que o tempo livre de aposentado será preenchido exclusivamente por atividades de lazer" (Duarte \& Mello-Silva, 2009, p. 48).

Como afirmamos anteriormente, a grande maioria dos docentes declarou a intenção de continuar trabalhando depois da aposentadoria. Esse dado tornou-se mais significativo quanto consideramos as opções de trabalho que apresentaram, as quais sintetizamos em três categorias: 1) Continuar o trabalho vinculado a uma universidade ou faculdade; 2) Realizar trabalho acadêmico sem vínculo institucional; e 3) Trabalhar em atividades não acadêmicas. Com base nessa categorização, sistematizamos os resultados de forma a permitir avaliar se a diferença de sexo, questões relacionadas à saúde e tempo de trabalho poderiam ser elementos importantes para direcionar a construção de planos de aposentadoria.

No que diz respeito a sexo, os resultados mostraram que há uma diferença significativa entre homens e mulheres quando se trata da categoria "Continuar trabalhando em atividade não acadêmica", como pode ser visto na Tabela 2 . 
Tabela 2. O que você planeja fazer quando se aposentar versus sexo ${ }^{8}$

\begin{tabular}{|l|c|c|c|c|}
\hline \multirow{2}{*}{\multicolumn{1}{c|}{ Planos após aposentadoria }} & \multicolumn{2}{c|}{ Masculino } & \multicolumn{2}{c|}{ Feminino } \\
\cline { 2 - 5 } & Freq. & $\%$ & Freq. & $\%$ \\
\hline Continuar trabalho acadêmico em universidade/faculdade & 14 & 25 & 9 & 22,5 \\
\hline Continuar trabalho acadêmico sem vínculo institucional & 6 & 10,7 & 5 & 12,5 \\
\hline Continuar trabalhando em atividade não acadêmica & 11 & 19,6 & 15 & 37,5 \\
\hline Atividade de lazer e diversão & 26 & 46,5 & 21 & 52,5 \\
\hline Atividade não específica & 12 & 21,4 & 5 & 12,5 \\
\hline Total & 56 & 100 & 40 & 100 \\
\hline
\end{tabular}

Fonte: Pesquisa direta.

Podemos notar que 37,5\% das professoras optariam por trabalhos não acadêmicos, em comparação a apenas 19,6\% dos professores. No mais, a Tabela 2 aponta que há uma tendência levemente maior entre as mulheres no sentido de planejarem inserir atividades de lazer e diversão em suas rotinas cotidianas. A escolha de trabalhos não acadêmicos por parte significativa das professoras pode estar relacionada ao fato de que são elas que tendem a sentir mais intensamente o impacto da jornada de trabalho. Uma vez que a universidade possibilita que o trabalho acadêmico seja realizado fora do espaço institucional, é comum os docentes adotarem esse recurso, especialmente as professoras. Com isso, elas tendem a se sentir, também, mais sobrecarregadas. Suas jornadas laborais costumam ter horário para iniciar, mas não para terminar, principalmente porque, muitas vezes, as demandas acadêmicas se entrelaçam com as exigências do cotidiano doméstico, fazendo elas experimentarem uma dupla jornada num mesmo intervalo temporal (Borsoi \& Pereira, 2011).

Com relação à saúde, sabemos que as professoras estão mais predispostas a manifestar problemas relacionados à saúde - principalmente aqueles de ordem psicoemocional - quando comparadas aos docentes do sexo masculino (Borsoi \& Pereira, 2011; Emiliano, 2008). Assim, é justificável analisar a relação entre as perspectivas de aposentadoria e aspectos referentes à saúde, considerando a diferença de sexo. $\mathrm{O}$ resultado pode ser visto na Tabela 3.

Tabela 3. O que planeja fazer quando se aposentar versus sexo e aspectos relacionados à saúde

\begin{tabular}{|c|c|c|c|c|c|c|}
\hline \multirow[t]{2}{*}{ Planos para aposentadoria } & \multicolumn{2}{|c|}{$\begin{array}{c}\text { Faz uso frequente de } \\
\text { medicação }\end{array}$} & \multicolumn{2}{|c|}{$\begin{array}{l}\text { Procurou médico ou } \\
\text { psicólogo nos últimos } \\
\text { dois anos por motivos de } \\
\text { ordem psicoemocional }\end{array}$} & \multicolumn{2}{|c|}{$\begin{array}{l}\text { Procurou médico ou } \\
\text { psicólogo nos últimos dois } \\
\text { anos por qualquer motivo }\end{array}$} \\
\hline & Fem. & Masc. & Fem. & Masc. & Fem. & Masc. \\
\hline $\begin{array}{l}\text { Continuar trabalho acadêmico em } \\
\text { universidade/faculdade }\end{array}$ & 21,7 & 16,7 & 23,5 & 4,3 & 20 & 25,6 \\
\hline $\begin{array}{l}\text { Continuar trabalho acadêmico sem } \\
\text { vínculo institucional }\end{array}$ & 13 & 16,7 & 5,9 & 4,3 & 8,6 & 9,3 \\
\hline $\begin{array}{l}\text { Continuar trabalhando em atividade } \\
\text { não acadêmica }\end{array}$ & 34,8 & 29,2 & 52,9 & 17,4 & 42,9 & 25,6 \\
\hline Atividade de lazer e diversão & 56,5 & 45,8 & 29,4 & 17,4 & 48,6 & 53,5 \\
\hline Atividade não específica & 13 & 20,8 & 5,9 & 4,3 & 14,3 & 14 \\
\hline $\mathrm{N}$ amostral & 23 & 24 & 17 & 23 & 35 & 43 \\
\hline
\end{tabular}

Fonte: Pesquisa direta.

O que se revela mais acentuado na Tabela 3 diz respeito, novamente, à tendência, agora mais visível, de as professoras planejarem atividades de trabalho fora do âmbito acadêmico. Aqui, chama a atenção, principalmente, o percentual de $52,9 \%$ das mulheres que continuariam trabalhando

8 A sistematização dos resultados dessa tabela levou em conta respostas múltiplas para cada um dos participantes da pesquisa. 
em atividades não acadêmicas e procuraram atendimento médico ou psicológico por queixas de ordem psicoemocional, contra 17,4\% dos homens que indicaram essa mesma relação. Nesse caso, alertamos para o fato de que, no geral, os docentes homens informaram apenas procurar atendimento médico como procedimento de rotina, o que inviabilizou a identificação de alguma queixa clínica mais específica. É preciso ressaltar que, mesmo quando não discriminamos o tipo de problema que motivou o atendimento médico ou psicológico, as professoras permaneceram em maior número $(42,9 \%)$ no que se refere a planos de dedicação ao trabalho fora da docência. Entretanto, vale considerar que também ocorre um aumento no percentual de homens (25\%) que tenderiam a buscar atividades produtivas fora do universo acadêmico, ao levarmos em conta a relação com questões associadas à saúde.

Nesse caso, os problemas de saúde indicados pelos docentes não apresentavam relação direta com o tempo de trabalho ou a idade, mas com determinadas características do próprio trabalho e, também, com a maneira como esses professores e professoras se relacionavam com suas atividades acadêmicas ${ }^{9}$. Dessa forma, é possível deduzir que as situações de adoecimento podem levar os docentes a redimensionarem seus projetos de vida ao vislumbrarem suas aposentadorias. Isso se torna mais evidente nas falas de entrevistados que estiveram afastados de suas atividades por licença médica.

A questão é: o que é ser produtivo? Por isso que eu decidi me aposentar. . . Não vou dar aula em nenhuma universidade ou faculdade particular. Vou trabalhar em algum projeto social e trabalhar com cursos, capacitações, assessoria para entidades governamentais e não governamentais. . . mas nunca mais quero ser professora (Mulher, 52 anos).

A cada ano eu penso um negócio. Já pensei num comércio simples de comida, já pensei em papelaria. Esse ano eu estou mexendo num jardim lá em casa. Mexo nele de manhã e à noite. Já pensei, então, em ter uma floricultura. Quando eu me aposentar, eu quero fazer uma coisa completamente diferente do que eu faço hoje. Não quero dar aula, não quero continuar com pesquisa. Eu quero me desvincular de vez da universidade (Homem, 47 anos).

Eu fico contando os dias e as horas. Isso é triste. Quando a gente tem muita aporrinhação, a gente conta os dias para se aposentar. Não é não fazer nada. É ter tempo, ter companhia e disposição para fazer coisas agradáveis (Mulher, 49 anos).

Nos relatos apresentados, é significativo que os entrevistados tenham sido enfáticos: "nunca mais quero ser professora", "não quero dar aula, não quero continuar com pesquisa", ou, ainda, "fico contando os dias e as horas". Esses docentes destacaram que mantêm o desejo de continuarem produtivos e que não vislumbravam a aposentadoria como uma etapa da vida em que o trabalho estivesse ausente. A ênfase foi, sobretudo, no fato de que pretendiam excluir de suas vidas a rotina de trabalho típica da universidade, hoje considerada muito exigente em termos de produtividade, como apontam Alvarez (2004), Borsoi (2012), Pizzio e Klein (2015) e Sguissard e Silva Junior (2009).

Do que podemos notar, até aqui, a grande maioria dos professores e professoras apontaram que suas perspectivas de aposentadoria giravam em torno de alguma forma de trabalho, mais frequentemente fora do âmbito da universidade. Aqui levamos em conta, no fundamental, situações em que os docentes referiam-se ao seu futuro como aposentados, sem considerarmos o tempo de trabalho. A sistematização dos resultados quantitativos para analisar esse aspecto não apontou

9 Sobre essa questão específica, sugerimos consultar Borsoi e Pereira (2013).

\section{0}


que o tempo de vínculo pudesse ser significativo na definição de planos para a aposentadoria ${ }^{10}$. No entanto, ao analisarmos o conjunto das entrevistas, foi possível notar que os docentes que se encontravam diante da possibilidade mais efetiva de desligamento da universidade evidenciavam mais fortemente a necessidade de se manterem trabalhando, bem como expressaram certa dificuldade de se desvincularem das atividades acadêmicas. Um deles afirma:

Agora, quero me aposentar da universidade, mas deixar de trabalhar eu não consigo. Primeiro, porque eu preciso trabalhar. Eu tenho uma família grande que depende da minha situação financeira. Por outro lado, me considero jovem, apesar de ter quase 60 anos. Então, estou em condições de trabalhar sem problema nenhum. Pelo andar da carruagem, só saio aos 70 anos (Homem, 57 anos).

Uma professora revela o desconforto ao se dar conta de que já poderia se aposentar. Seu relato é bastante esclarecedor.

Acho que fiquei um pouco assustada. Não sei como explicar isso. A questão da aposentadoria no nosso país é um negócio complicado. Você se torna inativo. Acho esse nome tão feio! É uma vida inteira que está acumulada ali. Aí, eu estava preocupada com isso, estava preocupada em parar uma atividade que eu gosto muito de fazer. . . O que eu iria fazer depois, se o que eu sei fazer direito é ser professora?. . . Eu penso em pedir minha aposentadoria, oficializar, continuar como professor voluntário, trabalhando na pós. Eu adoro a graduação, não vou tirar ela toda fora, mas ficaria um pouco mais na pós. Trabalharia mais uns quatro, cinco anos. É nesses quatro, cinco anos que eu vou acertar minha vida para os próximos anos (Mulher, 56 anos).

Outro professor, de 56 anos, responde que não sabe o que fará quando se aposentar, e acrescenta: "quem se aposenta é arquivo morto; inclusive toda a política [existente no país] é deixar os aposentados sem perspectiva".

Expressões como "inativo" e "arquivo morto" - ambos "nomes feios" - podem dizer muito sobre o sentimento que envolve um trabalhador (docente ou não) quando se trata da aposentadoria. Afinal, esta é considerada "símbolo do envelhecimento na sociedade ocidental capitalista, pois remete à ruptura com o trabalho produtivo" (Bressan, 2011, p. 53). Na língua portuguesa, a palavra aposentar, etimologicamente, deriva de "hospedagem". Desse modo, remete "à noção de abrigarse nos aposentos, no interior da habitação, ou seja, cessar as atividades" (Bressan, 2011, p. 54). Essas considerações podem oferecer a dimensão das implicações que tem, para um trabalhador, a decisão de se aposentar, de lidar com a possibilidade real de se inserir no mundo do não trabalho. Essa decisão "repercute na reorganização da vida familiar e em novos vínculos afetivos, espaços de convívio, relacionamentos fora do mundo do trabalho, rotinas e até diminuição gradativa da atividade em diversos aspectos, além do laboral” (Bressan, 2011, p. 56).

Dessa forma, a rotina acadêmica, considerada exigente e, por vezes, massacrante no âmbito da universidade, de certo modo parece ser repensada por alguns professores e professoras. Os docentes que se encontravam próximos a se aposentar parecem sentir, de maneira mais evidente, o receio de se tornarem "arquivo morto", de nada terem para fazer - porque conhecem apenas o trabalho acadêmico -, de sofrerem redução objetiva no rendimento financeiro no médio e no longo prazo, de perderem vínculos com colegas de longa data. Esse é um conjunto de elementos que, seguramente, pode gerar, em qualquer trabalhador, sentimento de insegurança e dificultar a construção de planos concretos e mais viáveis de atividades que possam ser realizadas a partir da aposentadoria.

10 É importante lembrar que esse tempo de trabalho variava entre menos de quatro anos e mais de 25 anos. Portanto, é plausível a ideia de que esse grau de dispersão dentro do grupo analisado possa ter interferido, em alguma medida, nesse resultado. 
Para além disso, existem ainda as incertezas quanto a mudanças no regime brasileiro de Previdência Social, o que vem ocorrendo desde 1998. As reformas implementadas desde então têm restringido, de forma crescente, garantias relativas à aposentadoria, tanto para os trabalhadores do setor privado quanto para os servidores públicos, incluindo aqui os docentes das universidades públicas federais. Não sem razão, alguns professores e professoras ressaltaram as implicações que as políticas voltadas para reformas na esfera do trabalho e da previdência tinham sobre as decisões em torno de suas aposentadorias.

Diante dos resultados expostos até aqui, é possível constatar que, na realidade, os docentes não conseguem se planejar, de fato, para o momento em que terão que se desvincular da universidade, como apontou um dos entrevistados.

Não tenho plano, sabe por quê? Porque eu nunca vi alguém que tivesse planejado aposentadoria fazer o que planejou. A briga que eu tive aqui no departamento é que eu acho que nós tínhamos que preparar os professores, porque são nossos colegas, para se aposentarem. Hoje, temos pessoas aqui que estão completamente desesperadas. O professor é uma pessoa que é vista o tempo todo como professor (Homem, 42 anos).

Falas como "O que eu iria fazer depois, se o que eu sei fazer direito é ser professora?" e "O professor é uma pessoa que é vista o tempo todo como professor" podem sugerir algo como "uma vez professor, sempre professor". Ou seja, elas indicam que, no mundo acadêmico, há um forte componente de identificação com a profissão. Essa percepção tende a ocorrer com frequência entre trabalhadores com elevada qualificação. Em profissões como a de professores universitários, "há pessoas que se aposentam pela compulsória e continuam trabalhando, algumas vezes até a morte" (Khoury, Ferreira, Souza, Matos e Barbagelata-Góes, 2010, p. 160).

Entre os entrevistados, algumas falas curtas e enfáticas diante da pergunta sobre planos para a aposentadoria podem ser indicativas de situações parecidas com essa: "Não me aposentarei"; "Morrer"; "Acho que só me aposento quando der minha 'expulsória"; "Não pretendo me aposentar, só o farei quando surgir uma oportunidade considerada importante". Então - seja por apego à vida acadêmica, seja por receio de se verem inativos ou improdutivos, ou, ainda, por não conseguirem vislumbrar concretamente uma maneira de preencherem o tempo desobrigado da rotina universitária -, parece plausível que muitos docentes tenham expressado dificuldades em fazer planos que considerassem viáveis fora do ambiente acadêmico.

Aspectos como esses fazem muitos professores e professoras, após se aposentarem, retornarem à universidade na condição de voluntários, assumindo tanto atividades de ensino como de pesquisa. Além disso, há ainda os casos de docentes que recebem o título de professor emérito pela relevância de seus trabalhos. Na prática, essas são situações que possibilitam aos docentes continuarem ativos, trabalhando na instituição enquanto suas condições físicas permitirem, às vezes até a morte.

Sabemos que o trabalho é um dos pilares fundamentais da vida de um indivíduo, bem como da constituição de sua identidade. Dois aspectos se destacam para que ele tenha essa dimensão: o sentimento que o trabalhador tem de estar produtivo e o reconhecimento social oriundo de sua profissão (Bressan, 2011). No caso dos docentes, é notório que, na atualidade, a atividade acadêmica tem sido caracterizada, em grande medida, pelo que se conhece no meio universitário como produtivismo - que, por sinal, tem levado ao aumento dos casos de adoecimento entre professores e professoras. Em que pese essa consideração, o trabalho docente continua sendo percebido como motivos de gratificação e reconhecimento social (Borsoi, 2012; Mancebo, 2007; Vilela, 2010) e de sentimento de liberdade (Moreira, 2011).

O sentimento de liberdade pode estar associado ao grau de flexibilidade e autonomia no modo de organizar o trabalho. França, Menezes, Bendassolli e Macedo (2013) afirmam que esses 
dois elementos são fundamentais para que um indivíduo queira seguir trabalhando ao se aposentar. No caso dos docentes envolvidos na pesquisa, a maioria referiu cumprir parte de sua jornada de trabalho no próprio espaço doméstico, o que significa que eles podiam usufruir, em grande medida, de certa flexibilidade e autonomia no ordenamento de suas atividades - muito embora esse arranjo laboral (que impõe a ausência de limites entre o tempo de trabalho e o tempo do não trabalho) traga prejuízos aos docentes, tanto no que toca à saúde quanto ao modo de organizar a vida social e familiar, como apontam Borsoi e Pereira (2011).

Assim, alguns resultados vão ao encontro do que outros pesquisadores apontaram em relação a professores universitários. Moreira (2011) afirma que, para muitos docentes, a aposentadoria não é vista como o fim das atividades profissionais e nem como um benefício vinculado ao processo de envelhecimento. Isso é confirmado por Bressan (2011), que, por sua vez, destaca que a aposentadoria é parte da vida profissional e laboral dos indivíduos, bem como consequência do seu desenvolvimento natural. Além disso, Figueira et al. (2017) salientam que o ambiente de trabalho é o espaço em que os trabalhadores compartilham muitas de suas experiências, histórias e conquistas; é também, para muitos, o principal locus de construção de vínculos de amizades, o que significa que a aposentadoria pode se configurar, também, como o fim desses vínculos. Isso significa que é preciso haver preparação para lidar com uma realidade que exige do indivíduo que trabalha e de sua família um processo de ressignificação de suas vidas.

Essa consideração põe em tela a necessidade de que as próprias universidades e as associações ou sindicados promovam políticas e/ou programas específicos voltados para atender os docentes no que diz respeito às necessidades advindas da aposentadoria - tanto aqueles que estão se aproximando do momento de desligamento efetivo da instituição, quanto os que já se encontram aposentados.

Nesse caso, é fundamental que se considere, como aspecto central, que os docentes tendem a construir uma relação peculiar com seu trabalho, que passa tanto pela natureza da própria atividade como pelos vínculos que estabelecem com seus pares e, em particular, com seus alunos. Além disso, há o fato de que a carreira acadêmica confere a professores e professoras um reconhecimento social também peculiar que, por sinal, tem peso importante em suas vidas. Questões como essas tendem a integrar o rol de preocupações em torno da aposentadoria, principalmente quando o docente não tem clareza do que será posto no lugar do trabalho acadêmico.

O próprio Estatuto do Idoso (Brasil, 2003) prevê um conjunto de direitos que deve ser garantido pelo poder público às pessoas com mais de 60 anos. É interessante ressalvar que as regras atuais da Previdência Social determinam idade mínima de 55 anos para mulheres e de 60 anos para homens para se aposentarem. Sendo assim, os docentes que podem pleitear sua aposentadoria ou são considerados idosos ou estão próximos disso. Tendo em vista essa questão, cabe salientar que, entre os direitos apontados pelo estatuto, está a preparação dos trabalhadores para a aposentadoria, com antecedência mínima de um ano, por meio de estímulo a novos projetos, conforme seus interesses, e de esclarecimento sobre os direitos sociais e de cidadania.

Nesse sentido, a universidade em questão cumpre esse quesito ao desenvolver um programa voltado a todos os servidores - técnico-administrativos e docentes - visando prepará-los para o momento do desligamento definitivo da instituição. Esse trabalho de preparação consiste em palestras, atividades e dinâmicas que têm o propósito de possibilitar aos participantes refletirem sobre seu próprio trabalho e suas perspectivas e projetos de vida ao se aposentarem, o que inclui planos de atividades tanto produtivas, como culturais e de lazer, de maneira que possam se manter ativos.

Costa et al. (2016) apontam que programas como esses tendem a tornar a transição da vida ativa para a de aposentado menos traumática. Entretanto, os autores observam que eles estão voltados para os servidores que já estão a um ou dois anos da aposentadoria, o que é considerado um tempo muito curto para avaliarem os diversos aspectos implicados na nova etapa de vida, bem como para traçarem planos que possam ser efetivos. Diante disso, ressaltam que a temática da 
aposentadoria deveria ser tratada ao longo da vida funcional, como parte integrante da carreira profissional. Isso poderia ser feito a partir da organização de eventos, como seminários e palestras, e da criação de projetos de extensão que tratem a aposentadoria e o envelhecimento como processos inter-relacionados inerentes à vida de qualquer trabalhador.

Uma vez aposentados, os docentes perdem o elo formal com a universidade. É nesse momento que a associação ou sindicato da categoria pode ter um papel relevante, tendo em vista que continua sendo a instância à qual professores e professoras podem continuar formalmente vinculados. Destarte, ela não somente pode ser considerada fundamental como espaço de encontros entre docentes aposentados e ativos, como também pode atuar como promotora de programas específicos voltados para seus associados aposentados, a exemplo de atividades culturais ou mesmo acadêmicas.

\section{Considerações finais}

O objetivo deste artigo foi analisar as perspectivas que professores e professoras de uma universidade pública federal apontaram em torno do seu desligamento definitivo do quadro docente da instituição à qual estavam vinculados, ou seja, a aposentadoria.

Os resultados sugerem que os docentes, em sua maioria, tenderiam a continuar trabalhando, mostrando, com isso, certa dificuldade em vislumbrarem suas vidas fora da esfera do trabalho. Dentre as questões analisadas, chamou atenção o posicionamento das mulheres em relação ao tipo de trabalho que fariam. Diferentemente dos homens, elas foram as que manifestaram, com maior frequência, preferência por atividades não acadêmicas, sugerindo, desse modo, o desejo de romper, de maneira mais efetiva, com a rotina estabelecida pela instituição universitária. Essa percepção parece ser reforçada pelo fato de que as professoras são as que mais expressaram, também, interesse em procurar se envolver com atividades prazerosas e de lazer.

Importa destacar que as mulheres apresentaram mais queixas relacionadas à saúde, o que mostra que esse pode ser um elemento importante no planejamento para a aposentadoria. Isso é reforçado ao verificarmos que, em alguma medida, os docentes do sexo masculino também seguiram em direção semelhante, quando consideramos esse aspecto. Em geral, as queixas não estavam relacionadas ao tempo de trabalho ou à idade, portanto não podem ser associadas diretamente à proximidade da aposentadoria, mas, no fundamental, a características das próprias atividades acadêmicas.

É possível notar que, para quase todos, o momento de se aposentar foi percebido como uma continuidade da vida ativa e produtiva, independentemente do tipo de trabalho que fariam - acadêmico ou não - e da forma de vínculo que construiriam - formal ou não. Isso posto, a aposentadoria não pareceu estar associada, necessariamente, ao envelhecimento natural do corpo, mas a uma etapa da vida que pudesse oferecer aos docentes uma oportunidade de usarem, a seu favor, a experiência acumulada ao longo de suas carreiras na medida em que estarão mais livres para determinar "o que fazer" e "como fazer" em termos de trabalho. Obviamente, esse grau de liberdade vislumbrado por eles está relacionado a determinada segurança no que diz respeito à condição financeira - que, por sinal, surgiu como uma questão preocupante para muitos deles, tendo em vista a previsível redução salarial ao longo do tempo, assim como as incertezas relacionadas ao regime de Previdência Social que regulamenta as aposentadorias.

Muito embora a maioria dos professores e professoras tenham expressado, com relativa convicção, seus planos e expectativas em relação à aposentadoria, isso pode não significar que eles estariam, de fato, se planejando para essa etapa da vida. $O$ receio diante da possibilidade concreta de rompimento do vínculo laboral com a instituição, por parte daqueles que estavam próximos do tempo necessário, ou já em condições para isso, aponta nessa direção.

\section{4}


Diante disso, julgamos importante destacar que é preciso ampliar os programas de preparação para aposentadoria já existentes nas universidades de maneira a possibilitar que os docentes, bem como os demais servidores, tenham condições de construírem planos mais efetivos para a vida após seu desligamento institucional definitivo. Isso significa a necessidade de que haja mais tempo dedicado à questão da aposentadoria, como também a aspectos relacionados ao processo de envelhecer, o que poderia ser realizado a partir de atividades regulares como seminários e projetos de extensão. Além disso, caberia também às associações ou sindicatos da categoria docente desenvolver ações que possam fornecer suporte àqueles que já se encontram aposentados, a exemplo de atividades culturais.

Para finalizar, convém lembrar que este artigo está fundamentado em uma pesquisa de amplo espectro que teve, como uma das questões abordadas, a aposentadoria docente. Dessa forma, a análise oferecida aqui está limitada ao recorte realizado no conjunto global dos resultados de maneira a destacar os elementos relacionados ao problema em tela. Em que pese essa limitação, acreditamos que este estudo pode, de um lado, oferecer elementos que permitam orientar programas e ações que tenham como alvo a aposentadoria docente e, de outro, levantar pontos de reflexão sobre essa questão entre os próprios professores e professoras, independentemente do tempo que os separa do momento do desligamento definitivo da vida acadêmica institucional. Afinal, o tempo do trabalho e o tempo do não trabalho são partes integrantes do processo de viver de qualquer trabalhador.

\section{Referências}

Alvarez, D. (2004). Cimento não é concreto, tamborim não é pandeiro, pensamento não é dinheiro! Para onde vai a produção acadêmica? Rio de Janeiro: Myrrha.

Bauer, M. W., Gaskell, G. \& Allum, N. C. (2002). Qualidade, quantidade e interesses do conhecimento. In M. W. Bauer \& G. Gaskell (Orgs.), Pesquisa qualitativa com texto, imagem e som: um manual prático (pp. 17-36). Petrópolis, RJ: Vozes.

Borsoi, I. C. F. (2012). Trabalho e produtivismo: saúde e modo de vida de docentes de instituições públicas de Ensino Superior. Cadernos de Psicologia Social do Trabalho, 15 (1), 81-100.

Borsoi, I. C. F. \& Pereira, F. S. (2011). Mulheres e homens em jornadas sem limites: docência, gênero e sofrimento. Temporalis, 11 (21),119-145.

Borsoi, I. C. F. \& Pereira, F. S. (2013). Professores do ensino público superior: produtividade, produtivismo e adoecimento. Universitas Psychologica, 12 (4), 1211-1233.

Brasil. (2003). Estatuto do idoso. Brasília, DF: Ministério da Saúde.

Bressan, M. A. L. C. (2011). A significação do trabalho e da aposentadoria: o caso dos servidores da Universidade Federal de Viçosa. Dissertação de Mestrado, Programa de Pós-Graduação em Economia Doméstica, Universidade Federal de Viçosa, Viçosa, MG.

Bressan, M. A. L. C., Mafra, S. C. T.; França, L. H. F. P.; Melo, M. S. S. \& Loretto, M. D. S. (2013). Bem-estar na aposentadoria: o que isso significa para os servidores públicos federais? Revista Brasileira de Geriatria e Gerontologia, 16 (2), 259-272.

Bruns, M. A. T. \& Abreu, A. S. (1997). O envelhecimento: encantos e desencantos da aposentadoria. Revista da ABOP, 1 (1), 5-33.

Costa, A. M. M. R, Micali, P. M., Huamaní, O. G., Costa, J. L. R. \& Lopes, R. G. C. (2016). Preparação para a aposentadoria. In J. L. R. Costa \& A. M. M. R. Fuzaro Junior (Orgs.), O que vamos fazer depois trabalho? Reflexões sobre a preparação para a aposentadoria (pp. 33-43). São Paulo: Cultura Acadêmica.

Duarte, C. V. \& Melo-Silva, L. L. (2009). Expectativas diante da aposentadoria: um estudo de acompanhamento em momento de transição. Revista Brasileira de Orientação Profissional, 10 (1), 45-54. 
Emiliano, N. (2008). Sociabilidades e adoecimento nas universidades: a saúde do trabalhador na Universidade Federal Fluminense. Dissertação de Mestrado, Programa de Estudos Pós-Graduados em Política Social, Universidade Federal Fluminense, Niterói, RJ.

França, L. H. F. P., Menezes, G. S., Bendassolli, P. F. \& Macedo, L. S. S. (2013). Aposentar-se ou continuar trabalhando? O que influencia essa decisão? Psicologia: Ciência e Profissão, 33 (3), 548-563.

Figueira, D. A. M., Haddad, M. C. L., Gvozd, R. \& Pissinati, P. S. C. (2017). A tomada de decisão da aposentadoria influenciada pelas relações familiares e laborais. Revista Brasileira de Geriatria e Gerontologia, 20 (2), 207-215.

Khoury, H. T., Ferreira, A. J. C.; Souza, R. A., Matos, A. P. \& Barbagelata-Góes, S. (2010). Por que os aposentados retornam ao trabalho? O papel dos fatores psicossociais. Revista Kairós de Gerontologia, 13 (1), 147-165.

Mancebo, D. (2007). Trabalho docente: subjetividade, sobreimplicação e prazer. Psicologia: Reflexão e Crítica, 20 (1), $74-80$.

Moreira, J. O. (2011). Imaginários sobre aposentadoria, trabalho, velhice: estudo de caso com professores universitários. Psicologia em Estudo, 16 (4), 541-550.

Pereira, J. R., Moraes, P. F., Pereira, U. V. \& Costa, J. L. R. (2016). Saúde, envelhecimento e aposentadoria. In J. L. R. Costa \& A. M. M. R. Fuzaro Junior (Orgs.), O que vamos fazer depois trabalho? Reflexões sobre a preparação para a aposentadoria (pp. 45-62). São Paulo: Cultura Acadêmica.

Pizzio, A. \& Klein, K. (2015). Qualidade de vida no trabalho e adoecimento no cotidiano de docentes do ensino superior. Educação $\mathbb{E}$ Sociedade, 36, 493-513.

Sguissardi, V. \& Silva Junior, J. R. (2009). Trabalho intensificado nas federais: pós-graduação e produtivismo acadêmico. São Paulo: Xamã.

Vilela, E. F. (2010). Vivências de prazer e sofrimento no trabalho docente: um estudo em IES pública de Belo Horizonte. Dissertação de Mestrado, Programa de Pós-Graduação em Administração, Faculdade Novos Horizontes, Belo Horizonte.

Endereço para correspondência

cristinaborsoi@uol.com.br, flaviliosp@yahoo.com.br
Recebido em: 04/10/2017

Revisado em: $12 / 11 / 2018$

Aprovado em: 16/11/2018 